\title{
MALLARD PARASITIZES SHARP-TAILED GROUSE NEST
}

STEPHEN W. LEACH, RR\#5, Site 28, Box 22, Prince Albert, Saskatchewan. S7K 3E5

On 12 May 1993, I observed and identified a Mallard hen flushing from the dense nesting cover plots planted by Ducks Unlimited. A good fix between my co-worker and myself produced the hen's nest within seconds of the initial flush. "Cass" (short for Cassandra) let out a loud comment of, "Oh, neat!" immediately upon observing the nest bowl. We found one Mallard egg and two Sharp-tailed Grouse eggs. All the eggs were cold, leading us to believe that the Mallard was attempting to lay her second egg. Variables such as first year of breeding, immediate need to lay egg or a high degree of predator disturbance could account for this parasitic nesting response. As far as I am aware a parasitized sharptail nest by a Mallard duck has never been documented. ${ }^{1,5,6}$ The file number for this particular nest was \#203.

Our work criteria included nest visits every seven days. So, on 19 May 1993 I was assigned the task of

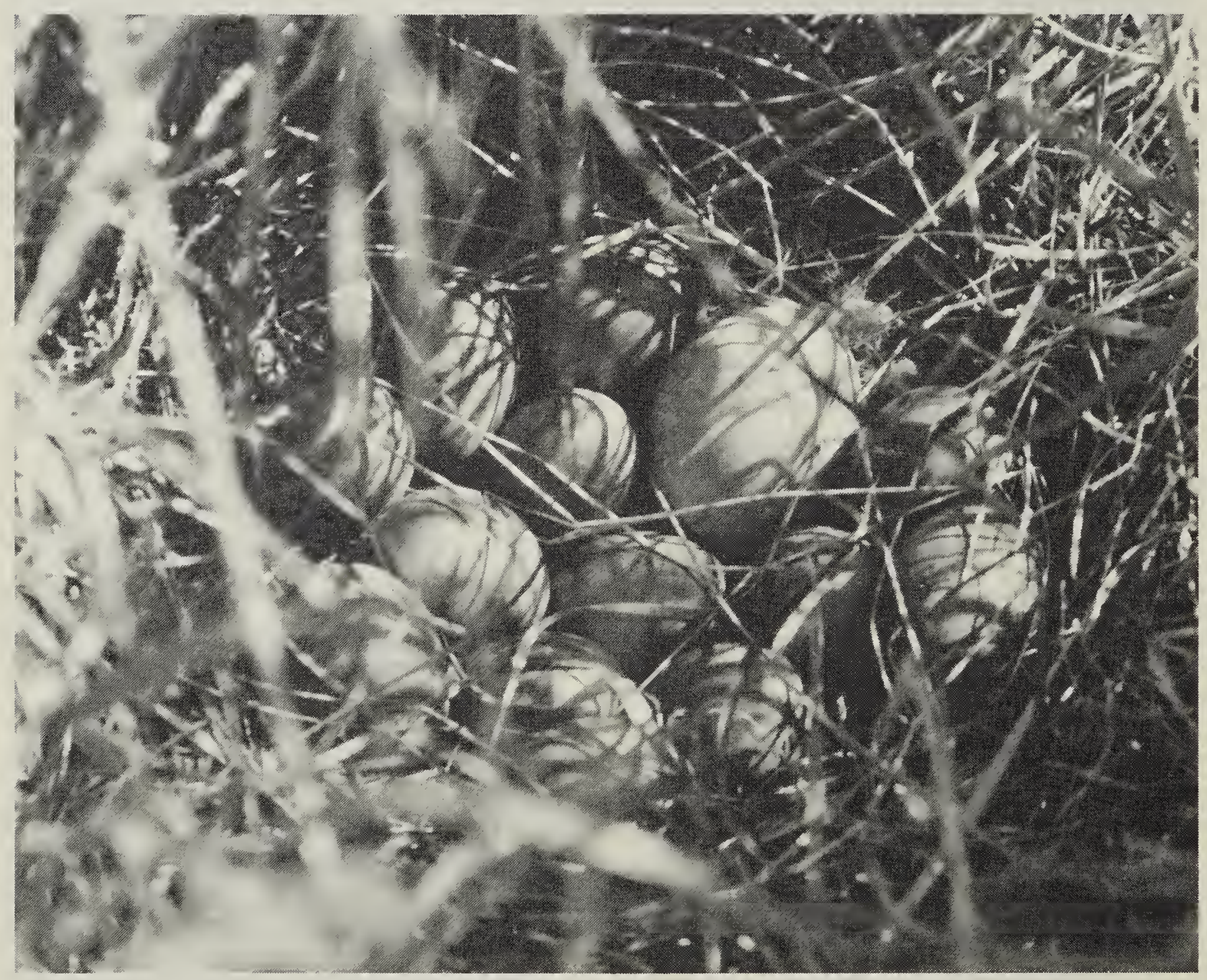




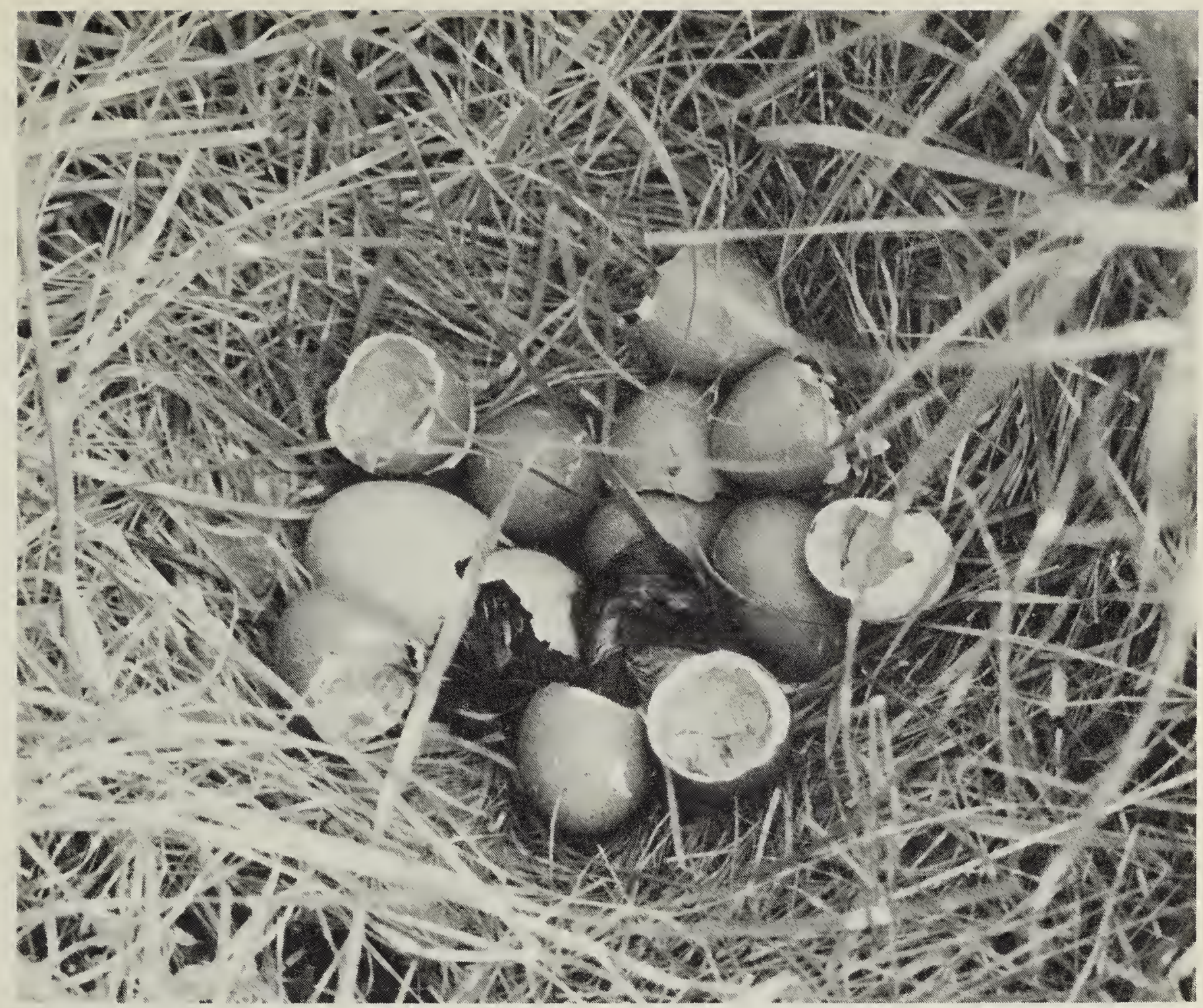

Mallard duckling in grouse nest.

Stephen W. Leach

revisiting nest \#203. Revisits for the purpose of research must be carried out in a manner which minimizes the disturbance of the incubating hen and the surrounding vegetation. ${ }^{3}$ । carefully approached \#203 and started wondering if the nest had been depredated since my feet were within one metre and my face directly over top of it. With my hands I carefully brushed aside the vegetation to expose the nest. An explosion of sound and blur of feathers was my next encounter. A sharptail hen came off the nest not more than a few centimetres from my face. After regaining my composure, I looked down and found eight Sharp-tailed Grouse eggs and one Mallard egg. I candled the Mallard egg and determined the stage of incubation at zero days. ${ }^{3}$ Dilemma time! Is this an active waterfowl nest according to our criteria? In a brief discussion with the senior biologist over the mobile radio, we decided that nest \#203 was non-active. Feeling great disappointment, I placed a large " $T$ " standing for "termination" at the top of \#203's data card.

On 26 May 1993 I happened to be performing revisits in close proximity to \#203. My curiosity got the best of me. As I cautiously approached \#203 I was better prepared for the extremely close flush of a sharptail hen. I was not prepared for what happened next. The hen jumped off the nest and headed directly toward me. She bumped into my leg and then immediately took to the air. I counted 12 sharptail eggs and one Mallard egg.

Candling of the Mallard egg determined the stage of incubation at four 
days. I felt a quick jog to the truck for my camera was necessary.

I decided from that moment on I would follow \#203's outcome personally.

On 2 June 1993, armed with a margarine container partially full of water, I headed towards \#203. The female flushed at approximately two metres. Again, 12 sharptail eggs and one Mallard egg were present. I placed one of the sharptail eggs in the container of water and determined the stage of incubation to be approximately 12 days. The percentage of the egg that is submerged determines this. ${ }^{4}$ Candling of the Mallard egg came to approximately 14 days incubation. Individual waterfowl eggs can adjust their incubation stage so that the clutch will hatch simultaneously (M. Gloutney, pers. comm., 1992). The Mallard egg seemed to be exhibiting this phenomena. It seemed odd to me, because the two species of incubating eggs were from different taxonomic families. Mallard hens incubate their eggs for approximately 28 days whereas, Sharp-tailed Grouse incubate for 24 days. ${ }^{2}$

The conclusion I came to after discussion with knowledgeable personnel on this topic was that the Mallard egg would not be able to adjust it's incubation stage to meet that of the sharptail eggs.

Due to my work schedule changing my next visit to the area near \#203 was not until 1 July 1993. Very high waterfowl nest mortality had me worried. I watched with utter enjoyment as the sharptail hen flushed within arm's length of me. Also, I experienced a strong feeling of relief that she and her eggs were still okay. The eggs were pipped, even the Mallard egg.

I covered up the eggs with nesting material and left. I returned four hours later with an audience of anxious biologists. This time when the hen flushed I was not the only one that got to enjoy observing her. The sight and sound of scattering chicks was music to my eyes and ears. The Mallard duckling had not quite fully made it out of the egg yet.

Further investigation on nest \#203 was not carried out. After discussion amongst our group on the chances of survival of the Mallard duckling, it was decided that the duckling would not likely survive more than 24 hours.

1. BUKER, J.B., J.N. DE WIT and W.A. VAN ZUILEN. 1986. Egg of Mallard Anas Platyrhyncos hatched by Longeared Owl Asio Otus. Limosa 59(1):40 In Dutch with English summ.

2. HARRISON, C. 1978. A field guide to the nests, eggs and nestlings of North American birds. Collins. $416 \mathrm{pp}$.

3. KLETT, ALBERT T., HAROLD $F$. DUEBBERT, CRAIG A. FAANES, and KENNETH F. HIGGINS. 1986. Techniques for studying nest success of ducks in the prairie pothole region. U.S. Fish Wildl. Serv., Resour. Publ. 158. $24 \mathrm{pp}$.

4. MCEWEN, LOWELL D., D.B. KNAPP, and E.A. HILLIARD. 1969. Propagation of Prairie Grouse in captivity. $J$. Wild. Mgmt. 33(2):276-282.

5. WANG, YING T. 1985. Mallard parasitizes Canada Goose nest and completes incubation. Jack-Pine Warbler 63(1):61 .

6. WILSON, STEVEN F. 1990. A mixed Wood Duck, Aix Sponsa,-Mallard, Anas Platyrhyncos, clutch. Can. FieldNat. 104(3):474-475. 